\title{
Mesenteric Vein
}

National Cancer Institute

\section{Source}

National Cancer Institute. Mesenteric Vein. NCI Thesaurus. Code C53055.

One of two veins (inferior or superior) that returns deoxyg enated blood from the intestines. 